\title{
DOCUMENTÁRIO E TECNOLOGIA: DUAS REALIDADES EM DESENVOLVIMENTO PARALELO
}

\author{
Patrícia Nogueira*
}

Resumo: Os últimos desenvolvimentos tecnológicos evidenciaram que as diferentes abordagens ao "real" no Documentário não são apenas resultado dos movimentos estéticos e sociais, mas também consequência do apparatus cinematográfico. Através da análise de vários documentários, tradicionais e interativos, busca-se compreender de que forma a tecnologia tem alterado o Documentário e o que deve ser preservado como caraterística de autenticidade inalienável.

Palavras-chave: documentário, tecnologia, interatividade, estética, autoria.

Resumen: Los últimos desarrollos tecnológicos han puesto de manifiesto que los diferentes abordajes de lo "real" en el documental no son únicamente el resultado de los movimientos estéticos y sociales, sino también la consecuencia del apparatus

cinematográfico. Mediante el análisis de varios documentales, tradicionales e interactivos, pretendo comprender de qué forma la tecnología ha alterado el documental y qué debe ser preservado como característica de autenticidad inalienable.

Palabras clave: documental, tecnología, interactividad, estética, autoría.

Abstract: The latest technological developments showed that documentary's different approaches to the "real" are not only the result of social and aesthetic movements, but also a consequence of the cinematic apparatus. By the analysis of several classic and interactive documentaries I intend to understand in what way technology has changed the documentary and what should be preserved as an inalienable characteristic of authenticity.

Keywords: documentary, technology, interactivity, aesthetics, authorship.

Résumé: Les derniers développements technologiques montrent que les différentes approches du "réel" dans le documentaire ne proviennent pas seulement des mouvements esthétiques et sociaux, mais sont également la conséquence de l'apparatus cinématographique. A travers l'analyse de divers documentaires, traditionnels et interactifs, je tenterai de comprendre dans quel sens et de quelle manière la technologie a modifié le documentaire et de dégager ce qui doit en être préservé comme caractéristique inaliénable de son authenticité.

Mots-clés: documentaire, technologie, esthétique, auteur.

\footnotetext{
* Doutoranda. Universidade do Texas - Austin International Program, Universidade do Porto Doutoramento em Media Digitais. 4200, Porto, Portugal.

E-mail: patnogueira@gmail.com
}

Submissão do artigo: 10 de junho de 2015. Notificação de aceitação: 20 de agosto de 2015 . 


\section{Introdução}

O Cinema é provavelmente uma das formas de arte mais tecnológicas. A combinação de uma confluência de disciplinas tanto Científicas (química, física, engenharia, ótica) como da área das Humanidades (literatura, pintura, teatro) levou a que inicialmente tenha sido colocado em primeiro plano o apparatus tecnológico, o que Mark Cousins denomina de "sobressalto técnico" (2004: 21). Nos primeiros momentos da história do Cinema foi a tecnologia que despertou um interesse imediato, na medida em que a promoção e a comercialização tinham como objetivo a experiência da máquina (de Lauretis, 1980:1). A máquina foi, de facto, introduzida entre o filme e o espectador. A ponderação do fator tecnológico torna-se por isso central para qualquer consideração sobre Cinema, onde se compreende o Documentário, como fenómeno cultural e histórico.

Além disso, nas origens do Cinema um aspeto central do fascínio pelo médium prende-se com a capacidade do público de reconhecer o mundo que habita. O poder da Fotografia de reproduzir uma espécie de recorte da realidade e congelá-la dentro de um enquadramento aumentou exponencialmente quando evoluímos para uma sucessão de imagens que restauram a sensação de movimento e de vida, ultrapassando o poder da imagem congelada. $\mathrm{O}$ público assistia a um mundo quotidiano aparentemente embalsamado, podendo seguir os acontecimentos e ações que até àquele momento pertenciam ao domínio do passado.

O surgimento do Cinema possibilitou, assim, um arquivo da realidade distinta de qualquer outra forma que o havia precedido e a possibilidade de reconhecimento das situações representadas neste arquivo criou um inegável fascínio sobre o espectador. A sensação de realismo transmitida pelo filme depende fortemente deste ato de reconhecimento que 
está na origem do Cinema e que permanece na tradição documental até à atualidade.

Mas não podemos ignorar os interesses económicos no desenvolvimento de qualquer tecnologia fílmica. Brian Winston (1996), por exemplo, acredita que a inovação e o desenvolvimento tecnológico no domínio do Cinema são impulsionados pelo mercado ou, pelo menos, acontecem em perfeita simbiose com os fatores económicos. Os espectadores têm de desejar o que a tecnologia pode proporcionar ainda antes da sua concretização. De Lauretis (1980) crescenta também que as novas tecnologias não emergem simplesmente, mas que são promovidas pelo mercado, criando necessidades que servem interesses comerciais.

O mesmo se passa com a emergência do multimédia e da realidade virtual:

"Without agreement on what these sytems are expected to do, there can be no mass market. This implies making na unsuspecting public familiar with a new device and persuading it not only of its merit, but of its ease of opperation. In this respect, the introduction of multimédia products into the home is a 'technology driven' push, rather than a 'culturally led' pull." (de Lauretis, 1980: 80-1).

Mas para lá das imposições económicas é possível identificar que os desenvolvimentos tecnológicos proporcionam novas abordagens estéticas e autorais, como são disso exemplo as mais recentes tecnologias digitais emergentes. Definidas as premissas iniciais do cinema, como a criação de uma gramática visual, mais do que alterar significativamente o resultado final, a maioria das inovações tecnológicas na indústria cinematográfica teve como objetivo expandir as práticas de produção (Eidsvik, 1988-9).

Mas no caso do Cinema Documental assistimos a um outro paradigma. Talvez devido aos escassos recursos económicos, o documentário alicerça-se numa tradição de experimentação (Nichols, 2001: 
83), de romper fronteiras ideológicas, estéticas e também tecnológicas, umas vezes apropriando-se das mais recentes invenções, outras vezes provocando essas inovações que depois são transferidas para outros contextos culturais. É esta busca constante pela novidade e pela experimentação que permite ao documentário reinventar-se e manter-se vivo.

Neste sentido, assistimos atualmente, mais uma vez, à reinvenção documentário. As condições de produção cinematográficas, cada vez mais acessíveis a um grande número de autores, a internet de banda larga e as codificações de vídeo que permitem grande qualidade de imagem num ficheiro de informação reduzida levaram novamente o documentário a romper fronteiras. Assistimos à transferência do cinema documental para o meio virtual, a uma fragmentação das narrativas, à construção do filme centrado nas audiências.

No entanto, como diz David Bordwell (2012), um filme já não é um "film", mas um ficheiro encriptado em linguagem binária. Além disso, a internet 2.0 favorece a interação entre produtores, realizadores e audiências, dando origem ao documentário interativo. Esta parece ser uma abordagem apelativa mas simultaneamente apresenta novos desafios ao documentário. A participação das audiências esbate as fronteiras da autoria e a interatividade pode ocultar o ponto de vista do documentário. Os novos contextos documentais de produção e distribuição estão a mudar a abordagem e a estética documental, levando-nos a (equacionar) uma nova fase, que Steven Shaviro (2010) denomina de pós-cinema.

\section{Documentário, da poética à intervenção}

A exploração da realidade vivida pelo cinema inicia-se com um inegável fascínio pelo exótico, desempenhado sobretudo pelo trabalho dos travelogues que se estendiam pelo mundo em busca de imagens do 
desconhecido. A representação do real conheceu uma nova etapa com o nascimento do Documentário. Em Nanook of the North (1922), Robert Flaherty apresenta uma nova representação da realidade, utilizando técnicas do cinema de ficção na construção de um ponto de vista sobre determinado fenómeno do mundo. No entanto, a curiosidade pelo desconhecido em zonas remotas do planeta prolonga-se no tempo e permanece durante o nascimento do Cinema Documental. À semelhança dos primeiros operadores de câmara, também Flaherty alimentava uma visão "romântica", parafraseando Paul Rotha (1983), sobre o conceito de "bom selvagem". Tal como confirmado por Frances Flaherty, companheira do realizador, este "loved primitive people, he loved their simplicity and their dignity, and the way they where free to be themselves" (Ellis e McLane, 2009: 23)

Mas Nanook of the North representa, sem dúvida, o resultado do primeiro esforço significativo de intersubjetividade na realização de documentários, que enfatiza um consenso de partilha entre realizador e sujeitos. Em virtude da capacidade de Flaherty de processar e revelar filme, o realizador podia mostrar sequências filmadas aos Inuit, de modo a obter a opinião dos sujeitos representados antes da montagem (Ellis e McLane, 2009: 13).

Quando a partir de década de 20 os documentaristas procuram novas formas de subjetividade e novas abordagens estéticas de representação do real, a tecnologia disponível permitia pouca flexibilidade. Nesta altura, o Cinema era pouco mais do que uma sequência de imagens fixas: a preto e branco, mudas e muito dispendiosas. As pesadas câmaras de $35 \mathrm{~mm}$ eram difíceis de operar, ruidosas e mantinham os planos presos ao chão através do tripé. Mesmo captando o som separadamente, o ruído da câmara interferia nas condições de gravação e o equipamento de som era ainda mais pesado e complexo do que o de captação de imagem.

Tais restrições não desencorajaram os primeiros realizadores. Pelo contrário, a história mostra-nos que as restrições tecnológicas 
impulsionaram os documentaristas a reinventar-se, com pontos de vista pertinentes e arrojados. A experimentação poética dos anos 20 surge da contaminação com outras expressões artísticas, dando origem a vários filmes das vanguardas modernistas. Sem grande possibilidade de mover a câmara, estes filmes são compostos com imagens quase exclusivamente fixas, nos quais os realizadores da época criaram narrativas eminentemente visuais. Imagens poéticas, misturadas, justapostas e sobrepostas, organizadas por uma montagem rítmica e apelativa, criavam metáforas e envolviam as audiências através das suas figurações emocionais do mundo envolvente. Esta abordagem permite que o filme crie um mundo único, seja através da indução de uma realidade ou exclusivamente através da forma.

O filme Regen (1929) insere-se nesta última abordagem de priorização das qualidades formais do filme sobre a temática. Antes de mais, o documentário centra-se na composição visual e na montagem rítmica, procurando padrões geométricos entre a chuva e os transeuntes, enquanto eles executam uma espécie de coreografia de negociação do espaço pela cidade. A narrativa, apesar de não muito definida, apresenta momentos distintos que lhe imprimem um certo ritmo. O trabalho de Joris Ivens poderse-á comparar a um poema ou a uma pintura em movimento.

Produzido praticamente com meios próprios e rodado durante meses, o documentário causa, no entanto, a sensação de que toda a ação decorre apenas durante uma tarde. Joris Ivens tinha a câmara carregada e pronta a filmar aos primeiros sinais de chuva. Alguns planos do filme foram até captados a partir da cama de Ivens que chegou a confessar "I slept with Anneke and with my camera" (Joris apud Schoots, 2000: 55). Mas já nessa altura o realizador procurava maior flexibilidade e foi na pequena Kinamo, uma câmara profissional de $35 \mathrm{~mm}$, que encontrou a possibilidade de fazer alguns movimentos:

With my camera held in my hand, the marvelous Kinamo of Professor Goldberg, I was, naturally, freed from the rigidity 
of a tripod, and I had given movement to what, normally, would have had to be a succession of fixed shots. Without knowing it, filming flexibly and without stopping, I had achieved a continuity. That day I realized that the camera was an eye and I said to myself, 'If it is a gaze, it ought to be a living one.' (Buckland, 2006: 92-93).

Com o advento do sonoro, à semelhança do que aconteceu nas narrativas de ficção, o cinema documental ganha também uma voz. Bill Nichols considera que a chegada do som ao documentário é uma questão de tecnologia, financiamento, estética e expectativas do público (Nichols, 1995). Mas é também preciso notar que muitos documentários se mantiveram mudos até aos anos 60, altura em que assistimos à introdução do som síncrono.

Consciente da importância do som John Grierson considerava que o microfone, tal como a câmara de filmar, podia superar um simples decalque da realidade. $\mathrm{O}$ fundador do movimento documental acreditava que a dimensão sonora seria capaz de atribuir ao documentário diferentes atmosferas e contribuir para a construção dramática do filme. No entanto, o autor também reconhecia uma falha essencial na precisão semântica do som. Grierson defendia uma estética sonora baseada num conceito de complementaridade entre imagem e som, que reforçava um compromisso com a estrutura dramática da narrativa (Rogers, 2015: 28-29).

A introdução do som no documentário permite uma transição das narrativas poéticas e evocativas para um discurso retórico, cimentado na propaganda de ideias políticas e sociais. Trabalhos como a série documental Why we fight (1952-53) e o filme The Plot that broke the plains (1936) procuram antes de mais manter a continuidade narrativa assente no argumento verbal, através da chamada "Voz de Deus" (Nichols, 2001: 105109). Nesta abordagem, a palavra prevalece sobre a imagem e os planos são muitas vezes meramente ilustrativos das reivindicações retóricas dos 
discursos, ao invés de permitirem que o potencial das sequências compostas por fragmentos imagéticos seja editado para alcançar o expoente máximo da narrativa cinematográfica.

A introdução do som no Documentário confere-lhe maior autenticidade mas simultaneamente desafia o realizador a evitar a dependência da dimensão sonora para marcar o ponto de vista do filme, levando a uma abordagem demasiado óbvia. Uma eventual alternativa baseou-se na substituição da narração off pelas entrevistas como forma de atribuir uma "voz" mais autêntica ao documentário.

O primeiro documentário a integrar o discurso real de cidadãos comuns sobre a sua vida quotidiana foi Housing problems (1935), produzido pelo British Film Institute. Arthur Elton e Edgar Anstey, realizadores do filme, concentraram-se no discurso da classe trabalhadora inglesa e, através de entrevistas com pessoas comuns, permitiram que os sujeitos se apresentassem "more fully and colorfully than was all together possible in silent film" (Elis e McLane, 2009: 69). O facto de os cidadãos expressarem para a câmara as preocupações do quotidiano representou uma inovação no documentário que até aí apenas considerava a voz autoral do documentarista. Igualmente inovador foi a atenção prestada à classe trabalhadora, levando o documentário a aproxima-se de questões e problemáticas sociais.

Estas duas abordagens - entrevistas e preocupações sociais - foram adotadas pelo discurso televisivo e mantêm-se até hoje, tanto no registo jornalístico como documental. No entanto, à medida que as tecnologias de captação de imagem e som evoluíram, o documentário passou a privilegiar narrativas na primeira pessoa e as entrevistas alcançaram uma abordagem mais intimista, num registo de conversas.

Em 1958, Michel Brault e Gilles Groulx realizaram para o National Film Board do Canadá o filme Les raquetteurs (1958), inaugurando uma nova e muito particular abordagem estética. O documentário é composto por 
um ágil trabalho de câmara, em grande parte sonorizado com som síncrono e sem qualquer narração, sem a interferência dos autores na tentativa de recusar a imposição de qualquer tipo de "verdade". Esta abordagem permitia uma maior imersão da audiência, dando aos espectadores a sensação de serem "transportados" para o local e de presenciarem os acontecimentos "tal como sucederam". Estavam, assim, criados os pressupostos do Cinema Direto, mas faltavam os instrumentos tecnológicos que permitiam esta abordagem.

A década de 60 revela-se especialmente desafiante para o Cinema Documental e são os próprios documentaristas que desenvolvem a tecnologia necessária para responder às suas aspirações estéticas, ao invés de apenas se apropriarem das novas ferramentas que iam surgindo. Em 1960, simultaneamente nos EUA (Robert Drew) e na França (Jean Rouch), os documentaristas tentam criar uma câmara leve, portátil, fácil de operar e silenciosa, que permitisse som síncrono. Só assim poderiam representar o mundo envolvente com a sensação de não-interferência que desejavam.

O documentário Primary (1960), produzido por Robert Drew e realizado por Richard Leacok, representou um avanço significativo na abordagem a acontecimentos reais, filmando a campanha das eleições primárias do partido democrático no Estado do Wisconsin com os candidatos Hubert Humphrey e John F. Kennedy (Elis e McLane, 2004: 212). As equipas do filme retratam não apenas os momentos públicos mas também os bastidores da campanha, acompanhando os acontecimentos em tempo real, sem interferência da equipa e sem recurso a entrevistas. O documentário conhece assim uma abordagem observacional (Nichols, 2001: 109-115). Neste registo notabilizou-se um plano sequência ininterrupto, com som síncrono, que acompanha o percurso de Kennedy pelas costas, desde o exterior de um edifício, entrando pela porta, o percurso do corredor e a subida de alguns degraus até ao palco, onde é recebido com aplausos. 
Quase simultaneamente em França, Jean Rouch, com a colaboração do sociólogo Edgar Morin, filmava Cronique d'un Eté (1961), utilizando a nova tecnologia de som síncrono essencialmente para gravar a discussão de ideias com os intervenientes e a captação de entrevistas. Apesar de Rouch, tal como Drew e Leacok, aproveitar a mobilidade das novas câmaras para se movimentar entre as personagens, o objetivo do realizador francês não era causar a impressão da não-interferência. Pelo contrário, Cronique d'un Eté é um filme autorreflexivo, na medida em que inclui no filme o próprio processo de produção e os realizadores aparecem frequentemente nas imagens, na tentativa de consciencializar sistematicamente a audiência para o facto de estar a assistir a um filme, a uma representação do real.

A partir dos anos 70 assistimos à introdução do VHS, que foi evoluindo ao longo da década de 80 , e à democratização da tecnologia. A transição para o vídeo representou um impacto significativo no documentário, tanto em termos de práticas de produção como de abordagem estética (McLane, 2012: 273). O baixo custo das cassetes de vídeo, quando comparadas com o preço da película e dos laboratórios de revelação, permitiu que mais pessoas passassem a produzir documentários e que as horas de imagem captadas aumentassem exponencialmente, apesar da diminuição da qualidade da imagem e do som. A fraca qualidade do vídeo, quando comparado com a película, trouxe acesos debates sobre o valor estético desta tecnologia (Elis e McLane, 2004: 259).

Simultaneamente, no manifesto "For an imperfect Cinema", o realizador cubano Julio Garcia Espinosa interrogava-se:

What happens if the evolution of film technology (there are already signs in evidence) makes it possible that this technology ceases being the privilege of a small few? What happens if the development of video-tape solves the problem of inextricably limited laboratory capacity? (Espinosa, 1979).

A resposta às questões de Espinosa encontra-se nos filmes de autorrepresentação desenvolvidos ao longo dos anos 70 e 80, aquando do 
aparecimento dos movimentos associados às minorias (feministas, LGBT, Afro-Americanos) que encontram no documentário um meio de representação alternativo às conceções das produções cinematográficas mainstream. Filmes com registos confessionais e íntimos, às vezes autobiográficos e narrados na primeira pessoa, resgatam histórias perdidas ou escondidas e exploram as experiências da repressão social. Muitos destes filmes, produzidos por ou com a colaboração de comunidades, apresentam uma experiência partilhada entre realizador e sujeitos.

Também os filmes ativistas, com agendas políticas ou sociais, se desenvolveram graças à democratização das tecnologias emergentes, permitindo que um número crescente de documentários fosse produzido em regiões normalmente sem meios financeiros para a produção cinematográfica, como os países da América Central (Mélane, 2012: 271). No entanto, o desejo de impressionar a audiência com a importância e urgência do tema por vezes negligencia as abordagens formais e artísticas, levando a que muitos dos filmes produzidos nestes contextos não consubstanciem obras de referência para o documentário, ainda que prevaleça o valor social das mesmas.

\section{A revolução digital}

Quando Espinosa previu "the possibility for everyone to make films" (Espinosa, 1979: 24) estava longe de imaginar que os desenvolvimentos tecnológicos iriam permitir que, de facto, qualquer pessoa com uma câmara digital e um computador pessoal conseguisse produzir e distribuir um documentário e, assim, adicionar ao panorama cinematográfico um novo ponto de vista. As câmaras de filmar DSRL - pequenas, acessíveis, fáceis de manusear e com enorme qualidade - permitiram que inúmeros aspirantes a realizadores, até então sem material para a produção cinematográfica, 
produzissem os seus projetos. A distribuição desses documentários também não se revela um problema na era digital, uma vez que muitos festivais de documentário dão visibilidade a realizadores emergentes e simultaneamente as plataformas digitais, como o Youtube e o Vimeo, servem de espaço privilegiado para a promoção e mesmo distribuição dos filmes.

À medida que o acesso a equipamento de produção, distribuição e exibição se democratiza o documentário expande-se e reconfigura-se de formas surpreendentes. No entanto, simultaneamente, a qualidade formal, estética e artística, sem esquecer as questões éticas, são colocadas em causa.

Mas o impacto das novas tecnologias no documentário revela-se através de formas mais amplas e complexas. Aliás "digital media redefines the very identity of cinema" (Manovich, 2006). Paralelamente aos desenvolvimentos tecnológicos que introduziram um novo apparatus cinematográfico, a partir dos anos 60 começou a ensaiar-se uma tendência para a interatividade computacional (Gere, 2008: 68). Com a entrada no novo milénio, a colisão destas duas tendências da atualidade acessibilidade tecnológica e interatividade - representou um impacto significativo nos modos de subjetividade de abordagem ao real e deu origem ao denominado "documentário interativo".

O conceito de documentário interativo encontra-se ainda a ser definido, tendo em conta as inúmeras configurações destes objetos que se situam entre o documental, a interatividade, a tecnologia e diversos elementos multimédia. A própria expressão "documentário interativo", usada originalmente por Whitelaw (2002), não é consensual. Parece-nos ser, no entanto, a que melhor define estes objetos digitais que pretendem uma abordagem criativa do real, com um ponto de vista definido, que utiliza a interatividade como forma de comunicação com o público e que não têm necessariamente de se encontrarem alojados na internet. Exemplo disso é o trabalho Immemoire (1997), do realizador Chris Marker, que concentra num 
CD-ROM diversos segmentos de vídeo que podem ser acedidos aleatoriamente, através de cliques em hiperligações.

Existem definições mais abrangentes para o documentário interativo, como é o caso da entrada no The Johns Hopkins guide to digital media and textuality (2014) escrita por Sandra Gaudenzi. Para a autora, qualquer trabalho que parta de uma intenção de documentar o real e utilize tecnologia interativa pode ser considerado um documentário interativo. Esta definição parece, no entanto, negligenciar que além de documentar a realidade, o documentário tem de imprimir um argumento sobre o mundo, apresentar um ponto de vista autoral, condição que vários teóricos (Bruzzi, 2000; Nichols, 2001) defendem como fundamental para estarmos perante um documentário e não uma mera reprodução da "realidade", como acontece nos trabalhos jornalísticos.

Pelas suas características, os documentários interativos são o que Umberto Eco denominaria de "Obras Abertas" (Eco, 1989), uma forma de arte com características que alteram radicalmente a relação entre autor e espectador, exigindo do público um grau muito maior de colaboração e envolvimento pessoal do que era solicitado nas obras tradicionais. Enquanto no documentário tradicional o espectador tem apenas uma narrativa de fruição, o documentário interativo proporciona ao público vários pontos de acesso e várias possibilidades narrativas.

No documentário interativo o espectador alcança a posição de utilizador, selecionando e apropriando-se dos segmentos que mais lhe interessam, sem que essas escolhas sejam necessariamente as mesmas do realizador. $\mathrm{O}$ número de possibilidades narrativas multiplica-se pelo número de acessos, já que cada experiência é individual e personalizada e a narrativa final só é construída no momento do acesso. Esta perspetiva desafia o princípio da coerência narrativa que sempre constituiu a estrutura das obras cinematográficas. Muitos documentários interativos apresentam estruturas 
de navegação rizomáticas, distribuindo os diversos segmentos de forma nãohierarquizada e descentralizada, o que proporciona ao espectador uma experiência livre. Neste sentido, tal como nota Carey Jewitt, "there is no internal grammar to be broken - there is no essential 'wrong order' because there is no prior reading path.” (2004: 187).

No entanto, é preciso notar, que as opções da audiência estão limitadas pelo tema e possibilidades de conteúdo oferecidas pelo autor do documentário. Apesar de não controlar a ordem pelo qual os conteúdos são visualizados nem a narrativa final o realizador é, ainda assim, quem define o tema, os conteúdos disponíveis e as premissas de interação, quem imprime o tal ponto de vista autoral, que consideramos uma caraterística inalienável no género documental.

Podemos também identificar uma tendência para narrativas mais fragmentadas, compostas por sequências que representam diferentes tempos e espaços. A verdade é que o Cinema, e em particular o documentário, sempre apresentou uma natureza fragmentada, construindo as obras através da junção de elementos discretos que se agregam num "todo", desde o próprio conceito de plano, à constituição de cenas (considerando o tempo e o espaço), alinhadas em sequências que juntas constituem a narrativa. No documentário interativo esta perspetiva pós-estruturalista atinge um outro nível, na medida em que os vários segmentos são apresentados separadamente e cabe ao público encontrar um caminho para os juntar e construir a sua própria narrativa. Este princípio coloca em causa a base ontológica da montagem cinematográfica, já que os elementos discretos têm de ser sequenciados numa ordem lógica de forma a construir um "todo", o que nem sempre se revela fácil considerando que o público desconhece a totalidade dos conteúdos propostos.

A ordem pela qual os segmentos são visualizados também deve ser considerada. A montagem cinematográfica, tal como provou Kuleshov nas suas conhecidas experiências, constituiu parte significativa da interpretação 
da obra. A combinação dos planos cinematográficos, das cenas e sequências e a relação que a audiência estabelece entre estes elementos atribuiu a estas imagens significados distintos de acordo com a ordem apresentada. Tal como o cinema privilegia a narrativa como a forma cultural de expressão da idade moderna, a revolução digital introduz o que Lev Manovich (2001) denomina de database, uma vez que "new media objects do not tell stories; they don't have beginning or end; in fact, they don't have any development, thematically, formally or otherwise which would organize their elements into a sequence" (Manovich 2001: 218).

A relação da obra com as audiências concretiza-se de diferentes formas. Os documentários interativos encontram-se em pleno desenvolvimento e a interação revela-se numa multiplicidade de conexões que exigem diferentes graus de participação e configuram envolvimentos diversos.

Provavelmente a relação comunicacional mais comum nos documentários interativos baseia-se em hiperligações, permitindo à audiência selecionar o conteúdo ao qual pretende aceder e a ordem pela qual os recebe. Um dos exemplos que ilustra o que Sandra Gaudenzi (2013: 4753) denomina de "hypertext mode" é o documentário Out my window (2010), realizado por Katherina Cizek para o National Film Board do Canadá. Trata-se de uma espécie de repositório de segmentos narrativos que permitem ao público conhecer as casas e as vidas de treze famílias em diferentes cidades do Mundo e perceber qual o impacto de viver em prédios de grande altura. As histórias são construídas através da composição de fotografias com uma perspetiva de $360^{\circ}$ e a narração sonora é composta com entrevistas das famílias.

Tal interação proporciona a sensação de navegação que alguns documentários interativos utilizam para criar narrativas paralelas e permitirem ao público traçar um caminho personalizado, na medida em que o espectador seleciona o percurso. No entanto, trata-se de uma obra fechada 
com conteúdos e duração pré-definidos pelo realizador. É o caso de Journey to the End of Coal (2010) que permite ao público encarnar a missão de um jornalista de investigação e empreender uma viagem desde Datong até à região Norte da China, para visitar as minas de carvão e aí conhecer as difíceis condições de trabalho dos mineiros que muitas vezes resultam em acidentes mortais. A estrutura deste documentário interativo consiste no rearranjo dos conteúdos à medida das escolhas do espectador, que vai avançando na narrativa através da seleção de caminhos.

Alguns documentários interativos apresentam uma estrutura mais rizomática, com múltiplas possibilidades narrativas, na intersecção entre o cinema e os videojogos. Aliás, a "gamificação" é outra das tendências do documentário interativo. As obras que se posicionam num registo de “conversational mode" (Gaudenzi, 2013: 39-46) apresentam-se estratificadas em níveis, obrigando o utilizador a cumprir determinados objetivos antes de avançar na narrativa, tal como se verifica numa estrutura de jogo. Através da definição de metas a atingir e da atribuição de "recompensas" o público sente-se encorajado a avançar e a conquistar trunfos que lhe permitem acesso a partes mais restritas do documentário e, consequentemente, proporcionam uma experiência mais envolvente.

Frequentemente, os documentários que apresentam esta abordagem baseiam-se num princípio de Inteligência Artificial e são evolutivos, ou seja as opções tomadas pelo utilizador influenciam a narrativa subsequente, contribuindo assim para uma sensação de possibilidades ilimitadas e tornando a experiência de navegação mais convincente.

Nestas obras o público assume o papel de protagonista do filme, na medida em que a interação com o interface do documentário possibilita que a ação progrida e, nesse momento, acontece a construção da narrativa. Podemos observar esta abordagem de interação no documentário Fort McMoney (2013) que reúne duas mil horas de filmagens de Fort McMurray, no Canadá, nas quais se incluem 55 entrevistas. A obra interativa utiliza 
uma estratégia de jogo que permite à audiência decidir o futuro da cidade virtual e alertar para o desenvolvimento sustentável na exploração da maior reserva de petróleo do mundo.

Outros documentários interativos utilizam como forma de interação a agregação de conteúdos enviados pelo próprio público, numa estratégia claramente participativa. Tal como O’Flynn (2012) nota é possível identificar uma tendência crescente para a interatividade através do uso da web 2.0 e do encorajamento dos recetores a assumirem um papel ativo tanto no financiamento (crowdfunding) como através da contribuição de conteúdos para os documentários. O resultado desta colaboração é a criação de arquivos digitais vivos, evolutivos e em constante atualização. De certa forma podemos enquadrá-los numa manifestação de Inteligência Coletiva, expressão cunhada por Pierre Lévy (1997) para definir uma forma de inteligência distribuída universalmente, constantemente melhorada, coordenada em tempo-real e resultado de uma efetiva mobilização das capacidades humanas.

Um dos exemplos mais conhecidos e bem-sucedidos desta relação com a audiência é o documentário A journal of insomnia (2013), também produzido pelo National Film Board do Canadá. A obra parte de quatro histórias de pessoas que sofrem de problemas de insónias e junta depois as contribuições de participantes que partilham deste mesmo problema, recolhidas através de uma entrevista marcada durante a madrugada, mediante o fuso horário da localização geográfica de cada participante. O documentário conjuga nesta altura mais de duas mil contribuições que também só podem ser acedidas durante a madrugada.

A abordagem dos documentários participativos transforma o espectador em colaborador e até em coautor da obra. Apesar de muitos autores expressarem alguma resistência à partilha da autoria podemos aqui citar Brian Eno (1991) que considera qualquer trabalho interativo incompleto até à intervenção da audiência. Assim, durante o processo, os 
elementos do público transformam-se simultaneamente em performers, autores e membros de uma audiência. Tal particularidade não retira aos autores originais da obra um forte sentido de autoria, na medida em que estes definem as premissas fundamentais de interação e o grau de participação do público. Assistimos sim a uma redefinição da noção de autor num conceito mais abrangente, que engloba o público como elemento fundamental do processo de criação e não apenas como recetor de uma mensagem. Eco (1989) considera as produções que contemplam a participação do público como "Obras em Movimento", possibilitando diversas intervenções pessoais. No entanto, este não é um convite indiscriminado a uma participação amorfa. O convite oferece ao público uma oportunidade devidamente orientada para inserir e manipular conteúdos na obra mas o resultado final permanece como uma obra concebida pelo autor.

Um outro modo de documentário interativo proposto por Sandra Gaudenzi (2013: 62-67) prevê a contribuição de conteúdos por parte das audiências através de elementos de georreferenciação ou dados biométricos referentes a um espaço geográfico específico, potenciando a experiência do lugar. É o caso do trabalho Greenwich Emotion Map (2005-6), de Christian Nold, que Gaudenzi referencia como exemplo de "experiential mode", uma vez que este permite aos utilizadores gravarem emoções e sentimentos num determinado local, para posteriormente o artista criar um "mapa de afetos" da cidade de Greenwich e apresentar como instalação em algumas galerias. Estes trabalhos encontram-se na intersecção entre o documental e as instalações artísticas e, não raramente, assemelham-se a obras de visualização de dados. Gaudenzi considera ainda que existe uma "experiência afetiva" que envolve o público no espaço através de um processo dinâmico e complexo.

Os dispositivos interativos, tais como o GPS, permitem ao público combinar dados de georreferenciação com imagens e sons para criar 
narrativas da experiência humana relacionada com determinado local, permitindo uma consciencialização da experiência do lugar. Nestes casos as tecnologias interativas representam um papel importante como ferramentas criativas de construção de narrativas, permitindo oportunidades colaborativas entre múltiplos utilizadores. A interação e experiências partilhadas contribuem, assim, para reforçar um sentimento de conectividade e de pertença tanto ao lugar como à comunidade participante. Um novo caminho que começa agora a desenhar-se é a fusão do documentário com a realidade virtual. Durante décadas a tecnologia já permitia simular ambientes virtuais, apesar dos conteúdos se limitarem comumente a demonstrações de realismo, sem grandes pretensões narrativas. Mas na edição 2015 do Sundance Film Festival foram apresentados onze projetos pensados para a tecnologia da realidade virtual (Tortum, 2015). Pelo menos três deles integram ambientes 3D gerados por computador, interatividade e um ponto de vista documental. As obras apresentam uma estratégia muito semelhante a videojogos, não só pela componente da interatividade mas principalmente porque a estética da imagem gerada por computador nos remete para um ambiente muito próximo daquele que é reproduzido nos jogos de entretenimento. Isto porque, apesar da animação e do documentário se terem aproximado desde 1918 (elGaudio, 1997), a imagem indexada ao real continua a configurar um forte elo de ligação da audiência a uma certa noção de "verdade".

Ao contrário das imagens captadas pela câmara no cinema tradicional, o documentário de realidade virtual coloca em causa a identidade indexical do cinema, uma vez que utiliza como material bruto imagens construídas: animação e imagens a três dimensões geradas e / ou trabalhadas por computador. O resultado final consiste na combinação de diversos elementos (cortados, sobrepostos, misturados, esticados, recriados) cujo aspeto poderá assemelhar-se de forma irrepreensível à "realidade" mas que nunca foram de facto captados por uma câmara. 
Tal não significa que aqui se negue o carácter documental das obras apresentadas na edição 2015 do Sundance Film Festival. O Project Syria (2014), por exemplo, da autoria de Nonny de la Peña, transporta o espectador para uma rua de Aleppo, na Síria, e após um ataque transfere-o para um campo de refugiados. O documentário apresenta um ponto de vista bem definido, quando pretende sensibilizar o público para a experiência de estar num campo de refugiados, tal como aconteceu a cerca de 3 milhões de sírios. Apesar do projeto ser criado em animação 3D, toda a criação virtual é baseada em acontecimentos, imagens e sons gravados na Síria. De acordo com a autora, a reconstituição destes espaços e a realidade virtual pretendem simular o cenário e evocar na audiência a sensação de estar no local (Peña, 2014). A interatividade limita-se a permitir ao público caminhar nestes cenários e observar os acontecimentos, sem causar qualquer alteração da narrativa.

Pelo contrário, 1979 Revolution (2013), da autoria do iraniano Navid Khonsari, apresenta uma estrutura de jogo, com múltiplas narrativas e cujas escolhas da audiência têm consequências na história (Parkin, 2013). O documentário reflete sobre a revolução que deu origem à criação do Estado Islâmico e foi construído com base na própria experiência do autor, enquanto testemunha ocular dos acontecimentos, e nas fotografias do fotojornalista francês Michel Setboun, que fotografou ambos os lados do conflito. Para Khonsari (Parkin, 2013) a estrutura de videojogo é a que melhor se adapta para acomodar diferentes histórias pessoais e as subtilezas de múltiplas perspetivas, provenientes de diferentes fações da narrativa histórica.

Por último, Assent (2013) lida com as questões da memória e inspirou-se num massacre que ocorreu no rescaldo do golpe militar chileno e ao qual o pai do autor, Oscar Raby, assistiu. O público é levado a colocarse no lugar da testemunha do massacre e, em determinados momentos, ao olhar para objetos ou locais recebe flashes de imagens que reconstroem a 
memória desse momento. Este mecanismo reproduz o stresse pós traumático do pai de Oscar Raby e, de certa forma, questiona os desafios da experiência. Deniz Tortum (2015), investigador assistente do MIT Open Documentary Lab, considera este trabalho extremamente pessoal e inovador na forma como utiliza os ambientes 3D, utiliza a interatividade e explora as “imperfeições” da memória.

Estes últimos trabalhos referenciados demonstram claramente que a indústria do Cinema começa a olhar para a realidade virtual como uma possibilidade de futuro. No entanto, todo o dispositivo criado altera significativamente aquilo que é considerado a "experiência do cinema" e cria novas exigências de distribuição, uma vez que a receção é individualizada e cada espectador necessita de um aparelho de realidade virtual.

As problemáticas ligadas à realidade virtual não se limitam às questões logísticas de distribuição. Nestes filmes corremos o risco que o dispositivo utilizado possa alienar o valor documental da obra. A construção da narrativa assemelha-se em tudo a um jogo de computador, com múltiplas possibilidades de navegação e uma estrutura evolutiva. Além disso, tal como nos jogos, a linguagem visual coloca a audiência no papel do protagonista do filme através do ponto de vista da câmara na primeira pessoa e do recurso a planos subjetivos, o que torna mais difusas as fronteiras entre realidade e ficção. Esta abordagem, ao invés de provocar um sentimento de alteridade como é pretendido pelos realizadores, poderá levar o público a distanciar-se dos acontecimentos reais e a encarar as situações apresentadas como parte de uma construção de puro entretenimento.

Também é fácil perceber que parte substancial do entusiasmo pelas novas narrativas advém da novidade tecnológica e da vontade de experimentar, o que torna difícil por vezes uma visão distanciada e crítica face a estes novos objetos. No entanto, não podemos negar que a realidade virtual exige novas formas de pensar o documental e novas estratégias 
narrativas, que irão intensificar a fusão, que de resto já se tinha iniciado, entre documental e videojogos.

\section{Considerações finais}

Tal como nos restantes média, o advento da internet e a revolução digital desafiam e alteram significativamente as formas de produção tradicional. Para o documentário, o paradigma do digital representa um desafio radicalmente diferente da introdução de outras tecnologias ao longo da história, uma vez que não se trata apenas de mais um passo no desenvolvimento linear da produção cinematográfica, mas do nascimento de uma nova forma de arte, tal como assistimos com o próprio nascimento do cinema. Mas é também verdade que o Documentário sempre se apresentou como uma abordagem criativa e em constante evolução, capaz de abraçar as mais variadas influências e reinventar-se a cada momento, tal como é demonstrado historicamente através dos modos preconizados por Bill Nichols (2001).

Atualmente, os realizadores encontram-se ainda a experimentar e a criar novos modos de abordagem ao real e às novas narrativas. Podemos questionar se os artefactos que surgem agora correspondem a uma evolução dinâmica do cinema documental ou se os novos média irão obrigar a uma rutura com as abordagens existentes para criar um espaço totalmente novo e independente. De acordo com Tom Perlmutter (2014), diretor do National Film Board do Canadá que lançou o programa de produção digital da instituição, o documentário interativo não irá substituir o cinema tradicional. Tal como "photography did not kill art; cinema did not kill theatre; television did not kill cinema. But the new form will grow in strength, maturity and impact" (Perlmutter, 2014). Pelo caminho ficarão muitos documentários que valerão apenas como parte de um processo experimental 
e evolutivo e que dificilmente figurarão na história como obras de referências mas levar-nos-ão a trabalhos mais consistentes.

Apesar do entusiamo que este tipo de filmes tem provocado, tanto junto do público como de alguns documentaristas, a verdade é que os filmes interativos representam uma mudança de paradigma na forma como nos relacionamos com o Documentário. Carolyn Miller chama a atenção para o facto de "users expect to be offered a selection of choices, but by offering them, you give up your ability to tell a linear story or to provide information in a fixed order" (Miller, 2004: 61). Neste sentido o realizador coloca em causa a sua autonomia e transfere para o espectador parte da conceptualização artística. Nos filmes interativos o utilizador ganha a possibilidade de criar uma estrutura discursiva e definir um rumo.

Coloca-se aqui a questão da autoria, uma vez que parte dos documentários interativos são construídos através de uma interação participante, na qual o público cria e partilha conteúdos. Mesmo quando essa participação não se verifica, a própria interação com o objeto fílmico pressupõe que a narrativa é fluida e personalizada para cada espectador, criada no momento de visualização. Esta estrutura não linear é disjuntiva do tempo narrativo de um filme tradicional e transforma a narrativa numa espécie de linha temporal alternativa.

No entanto, as inúmeras possibilidades narrativas e de contribuição do público não significam uma solicitação amorfa para a participação indiscriminada. $\mathrm{O}$ convite oferece ao espectador a oportunidade para uma participação orientada pela conceção autoral do realizador. Por outras palavras, o autor oferece ao público uma obra a ser completada e, mesmo sem ter pleno poder no resultado final, o realizador sabe que a obra continua a refletir o seu ponto de vista sobre o mundo, mesmo que tenha incorporado conteúdos particulares de contribuições externas à obra. Ou, como argumenta Eco em relação às obras em movimento, "The author is the one who proposed a number of possibilities which had already been rationally 
organized, oriented, and endowed with specifications for proper development" (Eco, 1989:19).

De qualquer forma encontramo-nos perante uma realidade nova em que a experiência do cinema se altera radicalmente: deixamos a sala escura, onde fruímos uma experiência pessoal num ambiente coletivo, e passamos para a frente de um ecrã, onde usufruirmos de uma experiência individual num ambiente partilhado.

Nota: trabalho de investigação financiado pela FCT - Fundação para a Ciência e a Tecnologia no âmbito da Bolsa de Doutoramento SFRH/BD/93138/2013

\section{Referências bibliográficas}

BORDWELL, David (2012), Pandora's digital box: films, files, and the future of movies, Madison, Wisconsin: The Irvington Way Institute Press.

BRUZZI, Stela (2000), New documentary: a critical introduction, London: Routledge.

BUCKLAND, Michael (2006), Emanuel Goldberg and his Knowledge Machine: information, invention, and political forces, Califórnia: Libraries Unlimited

COUSINS, Mark (2005), Biografia do filme, Lisboa: Plátano Editora.

DE LAURETIS, Teresa (1980), The cinematic apparatus, Londres: Macmillan. 
ECO, Umberto (1989), The open work, Massachussetts: Harvard University Press.

EIDDSVIK, Charles (1988-9), "Machines of the invisible: changes in film technology in the age of vídeo" in Film Quarterly, 42 (2), ed. Inverno.

ELGAUDIO, Sybil (1997), "If truth be told, can toons tell it? Documentary and Animation" in Film History 9:2, p. 189-199

ELLIS, Jack C. e MCLANE, Betsy A. (2009), A new history of documentary film, Nova Iorque: Continuum.

ENO, Brian (1991), "On writing space" in ARTFORUM, v. 30 n. 6, Nova Iorque, pp. 13-14.

ESPINOSA, Julio G. (1979), "For an imperfect cinema" in Jump Cut: A Review of Contemporary Media, (20), p. 24-26.

GAUDENZI, Sandra (2013), The Living Documentary: from representing reality to co-creating reality in digital interactive documentary. Londres: University of London.

GAUDENZI, Sandra (2014), "Interactive documentary" in The Johns Hopkins Guide to Digital Media, JHU Press, p. 552.

GERE, Charlie (2008), Digital culture, Londres: Reaktion Books.

JEWITT, Carey (2004), "Multimodality and New Communication Technologies" in Philip LeVine e Ron Scollon (Eds.), Discourse and techology: multimodal discourse analysis, Washington D. C.: Georgetown University Press, pp. 184-195.

LÉVY, Pierre (1997), Collective intelligence, Massachussetts: Perseus Books.

MANOVICH, Lev (2001), The language of New Media, Massachussetts: The MIT Press.

MCLANE, Betsy A. (2012), A new history of documentary film, Second Edition, Nova Iorque: Continuum. 
MILLER, Carolyn H. (2004), Digital storytelling: a creator's guide to interactive entertainment, Oxford: Focal Press.

NICHOLS, Bill (2001), Introduction to documentary, Bloomington: Indiana University Press.

O'FLYNN, Siobhan (2012), “Documentary's metamorphic form: Webdoc, interactive, transmedia, participatory and beyond" in Studies in Documentary Film, 6(2), 141-157

ROGERS, Holly (ed.) (2015), Music and sound in documentary film, Nova Iorque: Routledge.

ROTHA, Paul (1983), Robert J. Flaherty: a biography, (ed.) Jay Ruby. Filadélfia: University of Pennsylvania Press.

SCHOOTS, Hans (2000), Living dangerously: a biography of Joris Ivens, Amesterdão: Amesterdam University Press.

SHAVIRO, Steven (2010), "Post-Cinematic affect: on Grace Jones, Boarding Gate and Southland Tales" in Film-Philosophy, 14(1), 1102.

WINSTON, Brian (1996), Technologies of seeing, Londres: BFI.

\section{Filmografia}

1979 Revolution, 2013, Documentário RV. Dir: Navid Khonsari. E.U.A: Ink Stories.

A journal of insomnia, 2013, Documentário Interativo. Dir: Bruno Choiniere, Philippe Lambert, Thibaut Duverneix e Guillaume Braun. Canadá: National Film Board of Canada. Disponível em: http://insomnia.nfb.ca/

Assent, 2013, Documentário RV. Dir: Oscar Raby. Austrália: RMIT University.

Cronique d'un Eté, 1961, Filme. Dir: Jean Rouch. França: Argos Films. 
Fort McMoney, 2013, Documentário Interativo. Dir: David Dufresne.

Canadá: National Film Board of Canada. Disponível em: http://www.fortmcmoney.com/

Greenwich emotion map, 2005-6, Instalação. Dir: Christian Nold. UK.

Housing problems, 1935, Filme. Dir: Edgar Anstey e Arthur Elton. UK:

British Commercial Gas Association

Immemoire, 1997, Documentário Interativo (CD-ROM). Dir: Chris Marker.

França: Centre George Pompidou.

Journey to the end of coal, 2010, Documentário Interativo. Dir: Samuel

Bollendorff e Abel Segretin. França: Honkytonk. Disponível em: http://www.honkytonk.fr/index.php/webdoc/

Les raquetteurs, 1958, Filme. Dir: Michel Brault e Gilles Groulx. Canadá:

National Film Board of Canada

Nanook of the North, 1922, Filme. Dir: Robert Flaherty. E.U.A \ França:

Les Frères Revillon.

Out my window,2010, Documentário Interativo. Dir: Katherina Cizek.

Canadá: National Film Board of Canada. Disponível em: http://outmywindow.nfb.ca/

Primary, 1960, Filme. Dir: Robert Drew. E.U.A.: Drew Associates.

Project Syria, 2014, Documentário RV. Dir: Nonny de la Peña. E.U.A: USC

School of Cinematic Arts.

Regen,1929, Filme. Dir: Joris Ivens. Holanda: Capi-Holland.

The plow that broke the plains, 1936, Filme. Dir: Pare Lorentz. E.U.A.:

Resettlement Administration

Why we fight, 1952-53, Série Documental. E.U.A.: U.S. Government. 
Patrícia Nogueira

\section{Webgrafia}

DE LA PEÑA, Nonny (2014), "Project Syria: an immersive experience". Disponível em: http://www.immersivejournalism.com/projectsyria-premieres-at-the-world-economic-forum/.

MANOVICH, Lev (2006) "What is digital cinema?". Disponível em: http://manovich.net/ind,ex.php/projects/what-is-digital-cinema.

NICHOLS, Bill (1995), "Documentary and the coming of sound". Disponível em: http://filmsound.org/film-sound-history/documen tary.htm.

PARKIN, Simon (2013), "A truly revolutionary video game, in The New Yorker". Disponível em: http://www.newyorker.com/tech/ elements/a-truly-revolutionary-video-game.

PERLMUTTER, Tom (2014), “The interactive documentary: A transformative art form". Disponível em: http://policyoptions.irpp. org/issues/policyflix/perlmutter.

WHITELAW, Mitchell (2002), "Playing games with reality: only fish shall visit and interactive documentary". Disponível em: http://mtchl.net/tag/documentary. 